\title{
Primary Teacher Attitudes towards Productive Struggle in Mathematics in Remote Learning versus Classroom-Based Settings
}

\author{
James Russo ${ }^{1, * \mathbb{C}}$, Janette Bobis ${ }^{2} \mathbb{D}$, Ann Downton ${ }^{1}$, Sharyn Livy ${ }^{1} \mathbb{D}$ and Peter Sullivan ${ }^{1}$ \\ 1 Faculty of Education, Monash University, Clayton, VIC 3800, Australia; Ann.Downton@monash.edu (A.D.); \\ sharyn.livy@monash.edu (S.L.); peter.sullivan@monash.edu (P.S.) \\ 2 Sydney School of Education and Social Work, University of Sydney, Camperdown, NSW 2006, Australia; \\ janette.bobis@sydney.edu.au \\ * Correspondence: james.russo@monash.edu
}

check for updates

Citation: Russo, J.; Bobis, J.; Downton, A.; Livy, S.; Sullivan, P. Primary Teacher Attitudes towards Productive Struggle in Mathematics in Remote Learning versus Classroom-Based Settings. Educ. Sci. 2021, 11, 35. https://doi.org/

10.3390/educsci11020035

Academic Editor: Palitha Edirisingha

Received: 5 January 2021

Accepted: 14 January 2021

Published: 21 January 2021

Publisher's Note: MDPI stays neutral with regard to jurisdictional claims in published maps and institutional affiliations.

Copyright: (c) 2021 by the authors. Licensee MDPI, Basel, Switzerland. This article is an open access article distributed under the terms and conditions of the Creative Commons Attribution (CC BY) license (https:// creativecommons.org/licenses/by/ $4.0 /)$.

\begin{abstract}
Given what is known about the importance of productive struggle for supporting student learning of mathematics at all levels, the current study sought to examine teacher attitudes towards student struggle when students learn mathematics in remote learning settings compared with classroom settings. Eighty-two Australian early years primary teachers involved in a professional learning initiative focused on teaching mathematics through sequences of challenging tasks completed a questionnaire inviting them to compare the two settings. Drawing on a mixed-methods approach, we found that teachers were more positive about the value of student struggle in classroom-based settings compared with remote learning settings. Qualitative analysis of open-ended responses revealed four themes capturing why teachers viewed efforts to support productive struggle in a remote learning setting as potentially problematic: absence of a teacher-facilitated, synchronous, learning environment; parents' negative attitudes towards struggle when learning mathematics; lack of social connection and peer-to-peer collaboration; and difficulties accessing learning materials. Suggestions for mitigating some of these challenges in the future are put forward.
\end{abstract}

Keywords: COVID-19; mathematics education; online teaching; parent attitudes; primary education; productive struggle; remote learning; teacher attitudes

\section{Introduction}

As was the case across the world, 2020 was an unusual year for Australian schools due to the COVID-19 pandemic. Schools in most states, including New South Wales, shifted to remote learning for the majority of Term 2, whilst schools in Victoria relied on remote learning for a far longer period, including the majority of Term 2, all of Term 3, and the beginning of Term 4-totaling around half of the school year. The current study uses a professional learning project involving teaching with sequences of challenging tasks as an opportunity to compare early years primary mathematics teachers' (Foundation, Year 1, Year 2) attitudes towards student struggle when learning mathematics in a remote learning setting with a classroom-based setting [1].

\subsection{The Importance of Productive Struggle in Learning Mathematics}

Productive struggle is fundamental to successful mathematics learning [2]. The National Council of Teaching Mathematics listed productive struggle as one of eight essential teaching practices and noted that "effective mathematics teaching supports students in struggling productively as they learn mathematics" [3] (p. 48). They defined productive struggle as students "struggling at times with mathematics tasks but knowing that breakthroughs often emerge from confusion and struggle" [3] (p. 52). Struggle provides students with opportunities to grapple with important mathematical ideas [4] and can be viewed as a natural part of learning mathematics [5]. 
Moreover, engaging with cognitively demanding tasks that allow for genuine struggle is something that all learners should be afforded. Indeed, it has been argued that an "essential component of equitable classrooms is providing all students with opportunities to engage in productive struggle" [6] (p. 196), and that "all students need to struggle with challenging problems if they are to learn mathematics deeply" [7] (p. 6). Such experiences can support students to develop "mathematical resilience" [8] (p. 217), and are congruent with a growth mindset, where students believe that they can develop mastery through sustained effort, practice, and support [9].

Livy et al. argued that productive struggle connects directly to "productive classrooms" [10] (p. 19), where students are given opportunities to work on complex problems and are supported to take risks, even if they do not ultimately solve the problem they are working on. This is affirmed by evidence that mathematics learning is not contingent on successful completion of tasks, but on having opportunities to engage with complex tasks before teacher instruction and to deeply contemplate the underlying mathematics, and on being encouraged to persist through challenge [11].

Perhaps not surprisingly given the emphasis placed on struggle in the mathematics education research and teacher professional learning communities, teachers in Australian primary schools tend to hold positive attitudes towards the value of student struggle when learning mathematics [12]. Moreover, there is evidence that exposure to pedagogies that view productive struggle as integral to mathematics learning, such as problem-based approaches to learning mathematics, can further enhance teacher attitudes. Livy and Downton presented evidence that pre-service teachers can become more aware of the value of student struggle through exposure to a lesson structure that facilitates student exploration of a problem prior to instruction [13]. Likewise, Russo et al. found that teachers who had been exposed to professional learning around such problem-based approaches to learning mathematics had more positive attitudes towards struggle than teachers who had not participated in such professional learning [12]. This is consistent with other research that suggests that teacher endorsement of student struggle is potentially malleable if they are given opportunities to observe such approaches being effectively employed [14].

In other words, the consensus in the literature is that finding ways to prompt and support productive struggle can support student learning of mathematics, and that teachers exposed to relevant professional learning tend to hold positive attitudes towards struggle, at least in classroom settings.

\subsection{The Influence of Learning Settings on Teacher Attitudes towards Struggle in Mathematics}

Attitudes capture how individuals think, feel, and act when expressing a view, either positive or negative, about a given topic. They have been described as more stable and cognitive than emotions, but less stable and cognitive than beliefs [15].

It is important to note that prior research into Australian primary teacher attitudes towards student struggle when learning mathematics through problem solving has taken place in the context of classroom-based learning environments; such positive attitudes may not translate to remote learning settings. In fact, we contend that there are at least four interrelated reasons as to why we would expect attitudes towards student struggle of primary school teachers, particularly early years teachers, to be less positive in a remote learning setting compared with a classroom-based setting. These reasons include the following: low teacher control over the learning environment; parents' negative attitudes towards struggle when learning mathematics; the lack of social connection and peer-topeer collaboration; and the relative emphasis on asynchronous learning in remote settings. These reasons are elaborated below.

First, holding a positive attitude towards student struggle when teaching mathematics through challenging tasks depends on maintaining a high level of control, which in this instance refers to a teacher's confidence and self-belief in their capacity to effectively facilitate student learning of mathematics [16]. It is likely that remote learning settings 
undermine this sense of control because much of the student's environment is beyond the scope of the teachers' influence.

Second, and related to this, parents of children in early years of school are likely to be central to shaping remote learning environments, frequently playing the role of a pseudo-teacher [17]. Parents may be reluctant to allow students to struggle and feel the need to provide immediate support to students [18]. This is likely due to a variety of reasons, including the comparative lack of pedagogical skill and knowledge of parents as educators [19]; parents prioritizing "doing over learning" in a remote learning environment as parents of young children juggle learning support with other responsibilities, including their own employment [20]; and parents being more likely to hold traditional attitudes towards learning mathematics, such as a preference for direct instruction followed by practice [21]. Teachers may anticipate (or experience) parents "pushing back" if they encourage student struggle in remote learning settings, leading to teachers being more reluctant to allow students to struggle in the first instance.

Third, although there is strong evidence that students often enjoy learning mathematics through problem solving and generally embrace challenge, it is also the case that the social component of learning mathematics and opportunities to learn collaboratively are important for supporting student engagement and for ensuring that students feel supported when engaging with challenging tasks [22]. One of the key components to students persisting through challenge is the reassurance that all students are simultaneously in the "zone of confusion" [23] (p. 9) or the "learning pit" [24]. Undermining this dynamic will likely result in teachers being less positive about struggle. Indeed, there is evidence that a lack of social support and opportunities to work with, and learn from, peers is a significant obstacle to learning mathematics through inquiry-based approaches in a remote learning setting [25].

Finally, although synchronous learning opportunities are possible in remote learning settings through various technology-facilitated platforms (e.g., Zoom, Webex) and likely to be a component of many school mathematics programs, Sullivan et al. argue that online learning is particularly conducive to asynchronous learning, specifically the preparation of instructional videos followed by independent practice [26]. Attempting to facilitate episodes of productive struggles in an online asynchronous learning context will likely amplify the three aforementioned issues compared with doing so in an online synchronous learning context; for example, teachers would have even less capacity to shape the learning environment, and students would likely feel even more socially isolated.

The current study examined teacher attitudes towards student struggle in a remote learning setting compared to a classroom-based setting, in a context of teachers being exposed to professional learning around the value of reform-oriented pedagogies. The two research questions investigated were:

1. Do attitudes towards the value of struggle when learning mathematics amongst early years primary teachers differ depending on the educational setting (remote versus classroom) being considered?

2. What are the factors that early years teachers attribute to differences in the role of struggle in a remote learning setting compared with a classroom-based setting?

\section{Materials and Methods}

\subsection{Context, Participants, and Procedure}

We have been supporting generalist, early years (Foundation-Year 2; 5-8-year-old students), primary school teachers across two school systems in Australia in the adoption of a student-centered pedagogical approach to mathematics teaching that can be characterized as structured inquiry [27]. This approach to teaching encourages students to engage in sequences of problem-solving tasks that are connected, cumulative, and challenging, and generally aligns with pedagogical principles of reform-oriented mathematics instruction [1,26]. The project was piloted in 2018 and began formally in 2019. 
The final project day for each site was held remotely in November of 2020, and teachers were invited to complete a post-program questionnaire describing their experiences of implementing the learning sequences in 2020. Eighty-two teachers across two sites (New South Wales, $\mathrm{n}=39$; Victoria, $\mathrm{n}=43$ ) completed the post-program questionnaire. One section of this questionnaire, the focus of the current paper, included three questions specifically developed to invite teachers to compare the role that struggle plays in learning in a remote learning setting as compared to a classroom-based setting.

- Q1. Teachers completed the six Attitude Towards Struggle items (see Section 2.2) following the prompt: "Thinking about students in a remote learning setting. Please indicate your level of agreement on each of the following statements".

- Q2. Teachers completed the six Attitude Towards Struggle items (see Section 2.2) following the prompt: "Thinking about students in a classroom setting. Please indicate your level of agreement on each of the following statements".

- Q3. Teachers completed the open-ended item: "In your view, what is the role of struggle in mathematics in remote learning settings compared with classroom-based settings? Please describe your view of similarities and differences in as much detail as possible".

\subsection{Measures: Attitudes towards Struggle}

Teachers' attitudes towards student struggle were assessed using an instrument previously developed by the authors, Attitude Towards Struggle [16]. The six items from the measure included in the current study were assessed on 5-point Likert scales, ranging from strongly disagree (1) to strongly agree (5). Three of the items were reverse scored (denoted by *). The six items were:

- Most students can't begin a challenging task without the teacher first explaining the maths. *

- There is value in "throwing them in the deep end", and having students tackle a task before the teacher explains the maths.

- Experiencing struggle is an important part of students doing mathematics.

- If a student doesn't get it, it is the teachers responsibility to "set them right" straight away. *

- Student confusion in the mathematics classroom amounts to a waste of instructional time. *

- Getting stuck but not giving up is key to students learning mathematics.

The maximum score on this measure is 30 and the minimum score is 6 . The measure has been previously shown to have acceptable reliability $(\alpha=0.74)$, and to be moderately correlated with enjoyment of teaching mathematics and being in a mathematics leadership role (see Russo et al. for further information about the measure's development) [16]. Examinations of histograms, skewness, and kurtosis statistics in relation to both administrations of the Attitude Towards Struggle measure in the current study suggested that scores tended to approximate a normal distribution.

\subsection{Approach to Data Analysis}

This study adopted a mixed-methods approach, drawing on both quantitative and qualitative analysis to answer the two research questions. Mixed-method researchers advocate the use of "whatever methodological tools are required to answer the questions under study" [28] (p. 7). As a result, the paradigm of pragmatism frequently underlies studies adopting mixed-method approaches, including the current study. Pragmatism has been described as:

A deconstructive paradigm that debunks concepts such as "truth" and "reality" and focuses instead on "what works" as the truth regarding the research questions under investigation. Pragmatism rejects the either/or choices associated with the paradigm wars, advocates for the use of mixed methods in research, and 
acknowledges that the values of the researcher play a large role in the interpretation of results [29] (p. 713).

In order to address the first research question, attitudes towards student struggle data were analyzed quantitatively, using SPSS Statistics, Version 25. Data were analyzed using a paired samples t-test, in order to compare scores on the remote learning and classroombased versions of the Attitude Towards Struggle measure. In addition, a follow-up analysis using an independent samples t-test was undertaken to examine whether differences in attitudes towards struggle across settings was related to site (Victoria versus New South Wales). This additional analysis seemed prudent given that Victorian schools spent substantially more time in lockdown compared with New South Wales schools, and may have had more opportunities to consider how to adjust to a remote learning context.

To address the second research question, data from the open-ended survey response were analyzed thematically, combining "theoretical thematic analysis" with "inductive thematic analysis" [30] (p. 84). Specifically, we began the analysis by familiarizing ourselves with the data and generating an initial list of codes. We then endeavored to match this initial list of codes, and the associated data extracted, to one of the four themes identified from the literature that would suggest that teachers may view struggle in remote settings as problematic: low teacher control over the learning environment [16]; parents' negative attitudes towards struggle when learning mathematics [18-21]; the lack of social connection and peer-to-peer collaboration [22,25]; and the relative emphasis on asynchronous learning in remote settings [26]. The remaining codes and codable extracts of data that could not be connected to one of these four a priori themes were then analyzed inductively, with additional themes identified and described. This resulted in a fifth theme, difficulties accessing learning materials, being identified. The final stage of our analysis involved reviewing, refining, and defining the full list of themes using an iterative process of moving between the data, the codes, and the themes. In part this involved refining the description of the four a priori themes identified in the literature so that they better reflected the data and codes. It was during this final phase that it was decided to combine the a priori theme concerning learning environment with the theme concerning synchronous and asynchronous learning. This seemed a more parsimonious and useful interpretation of the data, due to the difficulties distinguishing between codes belonging to these two themes. This combined theme was labelled: absence of a teacher-facilitated, synchronous, learning environment. It is worth noting that although for the sake of consistency this theme was framed in the negative (i.e., the relative inferiority of the remote learning environment), many teachers presented their response in the positive (i.e., emphasizing what was afforded in a classroom-based setting).

The final four themes that described the difficulties that teachers anticipate encountering when allowing students to struggle in remote learning settings were:

1. absence of a teacher-facilitated, synchronous, learning environment

2. parents' negative attitudes towards struggle when learning mathematics

3. lack of social connection and peer-to-peer collaboration

4. difficulties accessing learning materials

Some participant responses were coded to multiple themes. For example, one particularly extensive, thoughtful response was coded to all four themes. We present this response with codable extracts italicized, and the relevant theme to which the extract was coded to in parentheses. Note also that despite having multiple codable extracts relevant to a particular theme, any participant response was only counted once towards any given theme:

Struggle in the classroom setting may see a lower level of student anxiety and therefore more student risk taking when finding solutions as errors are seen as important reflection points and learning opportunities (1). The classroom culture supports students through resources such as anchor charts, concrete materials (4), peers' thinking and reasoning, gallery walks and fish bowls (3) which all act as enabling prompts/strategies 
for students to access $(1,3)$. It is unlikely students would have the same access to these in a remote learning setting. Parents may not have been exposed to multiple solutions/strategies when solving mathematical problems (2). In the classroom setting students are expected and encouraged to share their mathematical thinking and reasoning guided by targeted teacher questioning compared to parents and carers who may not feel confident with the mathematics required for the tasks or seeing their child struggle without jumping in to do it for them (2). Teacher Number 35 (T35)

\section{Results}

3.1. Research Question 1: Does Attitude towards the Value of Struggle When Learning Mathematics amongst Early Years Primary Teachers Differ Depending on the Educational Setting (Remote Versus Classroom) Being Considered?

The paired samples t-test revealed that teacher attitudes towards struggle when considering students in a classroom-based setting $(M=24.4, S D=3.58)$ were significantly more positive than attitudes towards struggle when considering students in a remote learning setting $(M=23.7, S D=3.55), t(81)=2.773, p<0.01, d=0.31$. A follow-up analysis revealed that differences in attitude towards struggle across settings were independent of whether teachers were from New South Wales schools $(M=0.97, S D=2.35)$ or Victorian schools $(M=0.44, S D=2.20), t(80)=1.062, p>0.05$.

We can conclude that teachers are more likely to hold positive attitudes towards allowing students to struggle when students are learning mathematics in classroom-based settings compared with remote learning settings, although the magnitude of the difference (as indicated by the effect size) is small. This finding is consistent with other research discussing how facilitating inquiry-based learning in mathematics is problematic in a remote learning setting [25]. We now consider our analysis of teacher responses to the open-ended item asking them to elaborate on similarities and differences of the role of struggle across the two settings.

3.2. Research Question 2: Does Attitude towards the Value of Struggle When Learning Mathematics amongst Early Years Primary Teachers Differ Depending on the Educational Setting Being Considered?

Teachers were asked to respond to an open-ended item asking them to describe the similarities and differences between the roles of struggle in a remote learning setting as compared to a classroom-based setting. A small group of teachers (12\%) described the importance of struggle in general terms, without making any explicit reference to educational setting. It may be that these teachers view the role of struggle as similar across the two settings, or it may be that they did not interpret the question as intended. The remaining teachers highlighted differences in the role of struggle across settings, with the broad consensus being that encouraging productive struggle was far more problematic in a remote learning setting compared with the classroom. Our analysis produced four themes that capture these differences. The frequency with which data responses were classified to each of these themes is summarized in Table 1, with an illustrative quotation provided. As is apparent from Table 1, the two themes, absence of a teacher-facilitated, synchronous, learning environment and parents' negative attitudes towards struggle when learning mathematics, were the most prevalent, with over half of teachers having their responses coded to at least one of these themes. 
Table 1. Summary of thematic analysis: Challenges associated with allowing students to struggle in remote learning settings.

\begin{tabular}{|c|c|c|}
\hline Theme & $\begin{array}{c}\mathrm{N}=77^{1} \\
\text { (Percentage) }\end{array}$ & Illustrative Quotation \\
\hline $\begin{array}{l}\text { Absence of a teacher-facilitated, } \\
\text { synchronous, } \\
\text { learning environment }\end{array}$ & $42(55 \%)$ & $\begin{array}{l}\text { At school we understand the struggle and the learning pit and } \\
\text { encourage the struggle and not to give up in the classroom. We know } \\
\text { when to come in and provide a prompt and we know when to hold a } \\
\text { prompt back. We know when to extend students and we know when } \\
\text { to support students. We have the knowledge and background in the } \\
\text { teaching and know each individual student and how they learn. (T14) }\end{array}$ \\
\hline $\begin{array}{l}\text { Parents' negative attitudes } \\
\text { towards struggle when } \\
\text { learning mathematics }\end{array}$ & $40(52 \%)$ & $\begin{array}{l}\text { In remote learning settings there was minimal struggle observed as } \\
\text { many parents jumped in and assisted their children if they were } \\
\text { experiencing any problems. Some parents had difficulty with letting } \\
\text { their children struggle. They tended to "spoon feed" their children, } \\
\text { wanting them to have instant success. The actual "learning" was } \\
\text { greatly diminished as the students did not do anything for } \\
\text { themselves. (T12) }\end{array}$ \\
\hline $\begin{array}{l}\text { Lack of social connection and } \\
\text { peer-to-peer collaboration }\end{array}$ & $16(21 \%)$ & $\begin{array}{l}\text { In a remote setting students are on their own and not able to work } \\
\text { with their peers as such. Feeling isolated may create anxiety and the } \\
\text { feeling that they are the only ones that may be struggling. (T11) }\end{array}$ \\
\hline $\begin{array}{l}\text { Difficulties accessing } \\
\text { learning materials }\end{array}$ & $12(16 \%)$ & $\begin{array}{l}\text { In a classroom students have many resources to use to assist their } \\
\text { thinking and working out. However at home, they may not has } \\
\text { access to useful resources. (T17) }\end{array}$ \\
\hline $\begin{array}{l}\text { Described importance of } \\
\text { struggle, no reference to remote } \\
\text { or classroom settings }\end{array}$ & $9(12 \%)$ & $\begin{array}{l}\text { The role of struggle is to teach students how to problem solve and } \\
\text { how to connect students to their prior knowledge and different } \\
\text { learning. If the student is explicitly taught for every question they'll } \\
\text { never be able to connect bigger learning and concepts to different } \\
\text { tasks. You want them using learnt skills to solve a range of problems. } \\
\text { Struggle allows them to develop that. (T23) }\end{array}$ \\
\hline $\begin{array}{l}\text { Described } \\
\text { struggle/problem-based } \\
\text { learning as more difficult in } \\
\text { remote learning settings, but } \\
\text { did not elaborate on why }\end{array}$ & $3(4 \%)$ & $\begin{array}{l}\text { The remote learning situation made the struggle phase difficult- not } \\
\text { being face to face, but we tried to overcome it by including topics and } \\
\text { activities that students were able to work through with some parent } \\
\text { support. (T60) }\end{array}$ \\
\hline
\end{tabular}

Note: ${ }^{1}$ Five participants did not respond to the open-ended item $(\mathrm{Q})$.

\subsubsection{Absence of a Teacher-Facilitated, Synchronous, Learning Environment}

The majority of teachers (55\%) described the absence of teacher-facilitated, synchronous learning as an impediment to allowing students to struggle productively in a remote learning environment vis-à-vis the classroom. This was often described in the positive - that is, that classroom-based settings allow teachers to closely monitor students as they are grappling with a task, and to support them as required:

I think struggle in a classroom setting is fine as the teacher monitors and knows the students and is able to prompt and reflect along the way with students so they know they are okay and supported. (T10)

The role of struggle in remote learning settings is different to the role of struggle in the classroom. This is because the teacher is able to facilitate and cater for the learning needs of every student in a more efficient and interactive way when they are in the classroom. (T27)

Other teachers framed their response in the negative-that is, by describing a relative lack of synchronous learning opportunities in remote settings that made monitoring difficult whilst students were exploring the mathematics:

It was harder to allow 'struggle' during remote learning due to limited time doing face-to-face lessons. (T45) 
The role of struggle in mathematics during remote learning was very hard to monitor as once the instructional time was over children worked off screen to complete tasks. (T51)

Interestingly, even when the students were given opportunities to work on mathematical tasks in "real-time" during a virtual learning session, teachers still noted the difficulties with knowing how much support to provide students. This highlights how interacting with students through virtual platforms (e.g., Zoom, WebEx) only provides limited information to the teacher:

I feel in the classroom teachers are able to see students' body language better and therefore understand their true emotions quicker than online learning. (T32)

[It is] much more difficult to get that sense of how students are performing or feeling during remote learning, [and] therefore [more] difficult to 'jump in' when students may need the support of the teacher. (T37)

This issue is amplified by students' relative reluctance to communicate how they are feeling about their learning during a virtual learning session, perhaps highlighting the increased self-consciousness and difficulties building rapport over a virtual platform:

If students did struggle, they were a bit reluctant to share their ideas during online lessons compared to a classroom setting. (T39)

I found that some students just assumed they could do the task and then didn't speak up or let the teacher know what was happening. (T47)

Again, this can be contrasted with a classroom-based setting:

Students have the opportunity to discuss their struggle with the teacher and assistance is more available than for students in remote learning settings. (T4)

Finally, several teachers described how it was the emphasis on growth mindset that normalizes struggle in the classroom setting, something directly attributed to the professional knowledge of the teacher:

The big difference would be at school we have posters that refer to the learning pit ... and teachers who have been given professional development (PD) about growth mindset. (T3)

Whereas at school, teachers have the background knowledge and understand the rationale of challenging tasks. We are aware of when to intervene and when to take a step back and allow the students to have a go. Therefore, this allows students to develop a growth mindset and not feel so anxious about attempting these tasks. (T15)

This anticipates our next theme, which considers the role of parents in shaping how much to encourage student struggle in remote learning settings.

\subsubsection{Parents' Negative Attitudes towards Struggle When Learning Mathematics}

Again, the majority of teachers (52\%) also described how it was parents' and carers' negative attitudes towards struggle when learning mathematics that undermined this pedagogical approach in a remote learning setting. As one teacher stated:

Unfortunately many parents do not share this view of struggling in maths and would lead their children through the task. This made it difficult to both plan and implement. (T61)

This led to teachers not pursuing tasks that would result in students struggling, in part to reduce the anxiety experienced by parents in their role as remote learning facilitators. This suggests that teachers were cognizant that the COVID-19 lockdown was a difficult period for families as they struggled to balance competing priorities [20]:

The explore phase was always easy. Parents required tasks that were quick and easy for students to complete independently. (T1) 
During home learning, it was hard to allow students to 'struggle' as parents weren't confident with home learning. Therefore, we provided them with straightforward open-ended tasks to ease anxiety and stress of parents more than children. (T19)

During remote learning we did not want to increase anxiety in the home for students and parents. Children were not all in an environment where they had support/or parents who are confident in teaching mathematics. Students were given 'more' of the content during remote learning. (T24)

However, the most frequently provided explanation connected to this theme is that parents, due to both their limited pedagogical knowledge and mathematical content knowledge, and their own educational background [21], often did not see the value in allowing students to struggle when learning mathematics:

Struggle at home can be problematic as parents often don't get this... They don't necessarily see it as learning or a pathway to learning. They think if they don't get it straight away it is 'too hard' or the teacher hasn't taught them properly. It can undo the good done at school in raising the 'challenge' bar. (T10)

It was harder to achieve as the parents tended to intervene ... Parents themselves struggled with this type of mathematics, it was commented on/questioned in nearly all of our parent teacher interviews. (T28)

Parents may not have been exposed to multiple solutions/strategies when solving mathematical problems [during their own schooling]. In the classroom setting students are expected and encouraged to share their mathematical thinking and reasoning guided at times by targeted teacher questioning, compared to parents and carers who may not feel confident with the mathematics required for the tasks, or seeing their child struggle without jumping in to do it for them. (T35)

A further explanation provided by teachers as to why struggle was difficult to manage in remote learning settings, which has already been alluded to, was the different relationship dynamics between children and their parents, compared with a teacher [19]. Either the student or parent (or both) might find it difficult to tolerate the student struggling:

[Students] asking their parents to help start them on the right track, crying about the task, not understanding the question and giving up. (T9)

I feel as though parents also have different relationships with their children compared to a teacher and student. I have found parents are more likely to step in and help their children. (T32)

Regardless of how much you explicitly explain a task to a parent and encourage them to let their child think for themselves, for a lot of parents, it would be their immediate instinct to help their child so that they don't struggle. (T15)

Our next theme considers an additional issue of interpersonal dynamics that explains difficulties facilitating struggle in a remote learning setting; that is, a lack of social connection and peer-to-peer collaboration.

\subsubsection{Lack of Social Connection and Peer-to-Peer Collaboration}

Around one-fifth of teachers (21\%) noted the lack of opportunities to connect to and collaborate with peers as an obstacle to student willingness to struggle in a remote learning setting. We know from prior research that the social isolation brought on by remote learning was one of the most significant challenges identified by students [25], so the confirmation of this theme was not surprising. A key aspect of learning through challenging tasks in classrooms is the expectation that all students will be in the "zone of confusion" [23] (p. 9) or "learning pit" together [24]. The relative isolation experienced by students during remote learning, even during synchronous virtual sessions, would undermine this shared experience: 
In a remote setting students are on their own and not able to work with their peers as such. Feeling isolated may create anxiety and the feeling that they are the only ones that may be struggling. (T11)

In the remote setting it would be difficult to discuss a task. Students chat with each other in the classroom setting and discuss possible strategies. Remote learning students may feel alone and in the pit and not know how to get out. (T13)

Some teachers noted that it was the interactive aspect of being in the classroom and discussing ideas with other students and the teacher that was key to episodes of struggle becoming productive:

Facilitating conversations between myself and their peers, the struggle becomes productive and often results in more meaningful learning. (T12)

I think that struggle in mathematics is much more beneficial to students in a classroom setting because they have each other to bounce ideas off. (T64)

Indeed, building a community of learners where students can learn from, and be supported by, other students is a central aspect of a problem-solving classroom more generally:

Remote teaching is [students] by themselves whereas the classroom setting [learning] is everyone's responsibility and that is where you see the students help each other and reflect on their learning. (T41)

In the classroom it is a lot easier to have the students work collaboratively allowing students who find maths challenging to learn from and listen to those more competent students. (T62)

The final theme to be considered is the difficulties accessing learning materials remotely.

\subsubsection{Difficulties Accessing Learning Materials}

The emergent theme not anticipated from our review of the literature was the difficulties accessing learning materials and resources in remote learning settings, noted by around one-sixth of teachers $(16 \%)$. This theme is notably less complex than the others discussed so far. Teachers noted that when struggling with a task in a classroom, students would tend to access concrete materials as a means of trying to better make sense of the mathematics. The lack of access to such materials in their home environment meant that a student was less likely to be successful with their learning:

Materials weren't as accessible at home as school. (T58)

Students may not have any concrete materials they are allowed to use to assist with their understanding of maths. (T46)

In a classroom students have many resources to use to assist their thinking and working out. However at home, they may not have access to useful resources. (T17)

\section{Discussion}

The COVID-19 pandemic resulted in shifts to remote learning in many countries around the world, including Australia, for large periods in 2020. Given the importance of productive struggle for facilitating mathematics learning [2,4], the current study examined teacher attitudes towards student struggle when learning mathematics in a remote learning setting compared with the classroom. It was found that teachers were more positive about the value of student struggle in classroom-based settings. Four themes captured why teachers viewed efforts to support productive struggle in a remote learning setting as potentially problematic: absence of a teacher-facilitated, synchronous, learning environment; parents ${ }^{\prime}$ negative attitudes towards struggle when learning mathematics; lack of social connection and peer-to-peer collaboration; and difficulties accessing learning materials. Difficulties 
facilitating productive student struggle was likely one of several interconnected reasons why the learning of mathematics in Australian primary schools was anticipated to be less effective during remote learning compared with classroom-based settings [26].

Although both the quantitative and qualitative analyses revealed that teachers considered struggle to be more challenging in remote learning settings compared with classroombased settings, the qualitative data emphasized this point far more emphatically. Whereas comparing scores on the Attitudes Towards Struggle measure suggested only a small impact of setting on teacher attitudes $(d=0.31)$ when responding to the qualitative item, the vast majority of participants $(87 \%)$ emphasized how much more difficult it was to support student struggle in a remote learning setting. This issue of Likert scale data and analysis of open-ended items being in tension has been noted elsewhere in other areas of mathematics education research, and was described by Bragg as a "methodological dilemma" [31]. This "methodological dilemma" may point to limitations with trying to operationalize complex psychological constructs such as teacher attitudes towards student struggle using Likert scales, even if the psychometric properties of such measures are ostensibly sound. It highlights the value of qualitative approaches to educational research, including thematic analysis, which allow for more direct and nuanced inquiry into an issue of interest.

Methodological limitations notwithstanding (e.g., a relatively small sample of teachers involved in a single professional learning initiative), the current study contributes to our understanding of the difficulties pursuing constructivist, inquiry-oriented approaches to mathematics learning in remote learning settings $[19,25]$. Moreover, our findings suggest several practical areas of focus to mitigate the challenges identified, particularly if remote learning were to continue into the future as an important aspect of primary mathematics instruction. First, schools should consider how they might continue to innovatively incorporate technology-facilitated platforms to allow for more synchronous discussion and interaction when students engage in mathematics lessons. For example, one project school decided during the second lockdown to treat two synchronous half-hour learning sessions split across two days as a single mathematics lesson, to maximize opportunities for follow-up discussion that reflected students' actual experience of working on a challenging task and incorporated student work samples (see Downton et al. for the detailed case study) [18]. Second, schools should be supported to provide professional learning to parent communities to emphasize the value of constructivist approaches to learning mathematics, including the importance of allowing students to struggle productively. Third, schools should be funded to provide necessary materials (e.g., concrete manipulatives) to support learning mathematics in the home environment. Finally, policy makers might consider allowing parents of school-aged children to participate in "learning bubbles" with one or two other families. In addition to removing some stress for parents associated with remote learning, this would allow students to work collaboratively on mathematical tasks, increasing their sense of social connectedness, furthering opportunities for them to explain their mathematical thinking, and increasing their willingness to embrace productive struggle, secure in the knowledge that another student is (or other students are) having a similar experience.

In terms of future research directions, it is notable that our study found no differences between teachers in New South Wales and Victoria, despite the time they spent facilitating remote learning being notably different. This was somewhat surprising, and the issue warrants further, more systematic, investigation. Future studies may consider analyzing whether there are differences in the perception of online teaching and remote learning amongst teachers with different levels of experience in this modality of teaching. It may be postulated that teachers more experienced with facilitating remote learning would hold more positive attitudes towards this modality, and adopt more ambitious pedagogical approaches, such as teaching mathematics through inquiry and encouraging students to struggle productively. 
To summarize, we found that teachers did indeed have more positive attitudes towards allowing students to struggle in classroom-based settings compared with remote learning settings, although this was borne out more emphatically in our qualitative analysis. It appears that a teacher-facilitated, synchronous learning environment and opportunities to work collaboratively with peers are paramount to facilitating productive struggle in mathematics. Moreover, parents lack of willingness to allow their children to struggle and difficulties accessing learning materials serve as further barriers to teachers allowing productive struggle in remote learning environments.

Author Contributions: J.R. was responsible for conceptualizing the paper, developing the methodology, analyzing the data, writing the first draft of the paper and finalizing revisions. J.R., J.B., A.D., S.L. and P.S. all contributed to conceptualizing the overall project, securing funding, designing and administering the teacher questionnaire, and revising and redrafting the paper. J.B., A.D., S.L., and P.S. contribution to the validation of the data analysis, and provided feedback on early drafts of the paper. All authors have read and agreed to the published version of the manuscript.

Funding: The research that formed the basis of this article was funded by the Australian Research Council, Catholic Education Diocese of Parramatta, and Catholic Education Melbourne (LP 180100611). The views expressed are the opinions of the authors who take full responsibility for the ethical conduct of the research and preparation of the report.

Institutional Review Board Statement: The study was conducted according to the guidelines of the Declaration of Helsinki, and approved by the Ethics Committee of Monash University (Project 10791).

Informed Consent Statement: Informed consent was obtained from all subjects involved in the study.

Data Availability Statement: Data is available from the authors on request.

Conflicts of Interest: The authors declare no conflict of interest.

\section{References}

1. Sullivan, P.; Bobis, J.; Downton, A.; Hughes, S.; Livy, S.; McCormick, M.; Russo, J. Ways that relentless consistency and task variation contribute to teacher and student mathematics learning. In For the Learning of Mathematics Monograph 1: Proceedings of a Symposium on Learning in Honour of Laurinda Brown; Coles, A., Ed.; FLM Publishing Association: Edmonton, AB, Canada, 2020; pp. 32-37.

2. Murawska, J.M. Seven billion people: Fostering productive struggle. Math. Teach. Middle Sch. 2018, 23, 208-214. [CrossRef]

3. National Council of Teachers of Mathematics (NCTM). Principles to Actions: Ensuring Mathematical Success for All; NCTM: Reston, VA, USA, 2014.

4. Warshauer, H.K. Strategies to support productive struggle. Math. Teach. Middle Sch. 2015, 20, 390-393. [CrossRef]

5. Smith, M.S. Redefining success in mathematics teaching and learning. Math. Teach. Middle Sch. 2000, 5, 378-382. [CrossRef]

6. Lynch, S.D.; Hunt, J.H.; Lewis, K.E. Productive struggle for all: Differentiated instruction. Math. Teach. Middle Sch. 2018, 23, 194-201. [CrossRef]

7. Hiebert, J.; Wearne, D. Instructional tasks, classroom discourse, and students' learning in second-grade arithmetic. Am. Educ. Res. J. 1993, 30, 393-425. [CrossRef]

8. Townsend, C.; Slavit, D.; McDuffie, A.R. Supporting all learners in productive struggle. Math. Teach. Middle Sch. 2018, 23, 216-224. [CrossRef]

9. Dweck, C.S. Mindset: The New Psychology of Success; Random House Digital, Inc.: New York, NY, USA, 2008.

10. Livy, S.; Muir, T.; Sullivan, P. Challenging tasks lead to productive struggle! Aust. Prim. Math. Classr. 2018, 23, 19-24.

11. Kapur, M. Productive failure in mathematical problem solving. Instr. Sci. 2010, 38, 523-550. [CrossRef]

12. Russo, J.; Bobis, J.; Downton, A.; Hughes, S.; Livy, S.; McCormick, M.; Sullivan, P. Elementary teachers' beliefs on the role of struggle in the mathematics classroom. J. Math. Behav. 2020, 58, 100774. [CrossRef]

13. Livy, S.; Downton, A. Exploring experiences for assisting primary pre-service teachers to extend their knowledge of student strategies and reasoning. J. Math. Behav. 2018, 51, 150-160. [CrossRef]

14. Russo, J.; Hopkins, S. Teachers' perceptions of students when observing lessons involving challenging tasks. Int. J. Sci. Math. Educ. 2019, 17, 759-779. [CrossRef]

15. Philipp, R. Mathematics teachers' beliefs and affect. In Second Handbook of Research on Mathematics Teaching and Learning; Lester, F.K., Jr., Ed.; Information Age Publishing: Charlotte, MV, USA, 2007; Volume 1, pp. 257-315.

16. Russo, J.; Bobis, J.; Sullivan, P.; Downton, A.; Livy, S.; McCormick, M.; Hughes, S. Exploring the relationship between teacher enjoyment of mathematics, their attitudes towards student struggle and instructional time amongst early years primary teachers. Teach. Teach. Educ. 2020, 88, 102983. [CrossRef] 
17. Di Pietro, G.; Biagi, F.; Costa, P.; Karpinski, Z.; Mazza, J. The Likely Impact of COVID-19 on Education: Reflections Based on the Existing Literature and Recent International Datasets; Publications Office of the European Union: Luxembourg, 2020.

18. Downton, A.; Hughes, S.; Russo, J.; Bobis, J.; Livy, S.; Sullivan, P. From confusion to clarity: Learning from a COVID-19 experience. under review.

19. Schuck, R.K.; Lambert, R. “Am I doing enough?” Special educators' experiences with emergency remote teaching in Spring 2020. Educ. Sci. 2020, 10, 320. [CrossRef]

20. Schieman, S.; Badawy, P.J.; Milkie, M.A.; Bierman, A. Work-Life Conflict During the COVID-19 Pandemic. Socius 2021. [CrossRef]

21. Lubienski, S.T. Traditional or standards-based mathematics? The choices of students and parents in one district. J. Curric. Superv. 2004, 19, 338-365.

22. Russo, J.; Minas, M. Student attitudes towards learning mathematics through challenging, problem solving tasks: “It's so hard-in a good way". Int. Electron. J. Elem. Educ. 2020, 13, 225-235. [CrossRef]

23. Clarke, D.; Roche, A.; Cheeseman, J.; Sullivan, P. Encouraging students to persist when working on challenging tasks: Some insights from teachers. Aust. Math. Teach. 2014, 70, 3-11.

24. Nottingham, J. The Learning Challenge: How to Guide Your Students through the Learning Pit to Achieve Deeper Understanding; Corwin Press: Thousand Oaks, CA, USA, 2017.

25. Kalogeroupoulos, P.; Roche, A.; Russo, J.; Vats, S.; Russo, T. Learning mathematics from home during COVID-19: Insights from two inquiry-focussed primary schools. under review.

26. Sullivan, P.; Bobis, J.; Downton, A.; Feng, M.; Hughes, S.; Livy, S.; Russo, J. Threats and opportunities in remote learning of mathematics: Implication for the return to the classroom. Math. Educ. Res. J. 2020, 32, 551-559. [CrossRef]

27. Alfieri, L.; Brooks, P.J.; Aldrich, N.J.; Tenenbaum, H.R. Does discovery-based instruction enhance learning? J. Educ. Psychol. 2011, 103, 1-18. [CrossRef]

28. Teddlie, C.; Tashakkori, A. Foundations of Mixed Methods Research: Integrating Quantitative and Qualitative Approaches in the Social and Behavioral Sciences; Sage: Thousand Oaks, CA, USA, 2009.

29. Tashakkori, A.; Teddlie, C. Handbook of Mixed Methods in the Social and Behavioural Science; Sage: Thousand Oaks, CA, USA, 2003.

30. Braun, V.; Clarke, V. Using thematic analysis in psychology. Qual. Res. Psychol. 2006, 3, 77-101. [CrossRef]

31. Bragg, L. Students' conflicting attitudes towards games as a vehicle for learning mathematics: A methodological dilemma. Math Educ. Res. J. 2007, 19, 29-44. [CrossRef] 